\title{
Footwear comfort: a systematic search and narrative synthesis of the literature
}

\author{
Hylton B. Menz ${ }^{*}$ (D) and Daniel R. Bonanno
}

\begin{abstract}
Objective: To provide a narrative synthesis of the research literature pertaining to footwear comfort, including definitions, measurement scales, footwear design features, and physiological and psychological factors.

Methods: A systematic search was conducted which yielded 101 manuscripts. The most relevant manuscripts were selected based on the predetermined subheadings of the review (definitions, measurement scales, footwear design features, and physiological and psychological factors). A narrative synthesis of the findings of the included studies was undertaken.
\end{abstract}

Results: The available evidence is highly fragmented and incorporates a wide range of study designs, participants, and assessment approaches, making it challenging to draw strong conclusions or implications for clinical practice. However, it can be broadly concluded that (i) simple visual analog scales may provide a reliable overall assessment of comfort, (ii) well-fitted, lightweight shoes with soft midsoles and curved rocker-soles are generally perceived to be most comfortable, and (iii) the influence of sole flexibility, shoe microclimate and insoles is less clear and likely to be more specific to the population, setting and task being performed.

Conclusion: Footwear comfort is a complex and multifaceted concept that is influenced not only by structural and functional aspects of shoe design, but also task requirements and anatomical and physiological differences between individuals. Further research is required to delineate the contribution of specific shoe features more clearly, and to better understand the interaction between footwear features and individual physiological attributes.

Keywords: Shoes, Foot orthoses, Comfort, Measurement

\section{Background}

Footwear plays an essential role in protecting the foot from trauma and facilitating efficient and pain-free movement when performing a wide range of routine, occupational, recreational, and sporting activities. The selection of footwear is influenced by economic, cultural and functional factors, with comfort frequently being reported as one of the most important considerations in a range of settings [1-3]. Comfort can be defined as the state of being physically relaxed and free from pain, although the mere absence of pain does not fully

\footnotetext{
* Correspondence: h.menz@latrobe.edu.au

Discipline of Podiatry, School of Allied Health, Human Services and Sport, La Trobe University, Melbourne, Victoria 3086, Australia
}

constitute the positive state of being comfortable. Rather, comfort is a broader construct which also incorporates the absence of other unpleasant physiological sensations (such as rough textures, extremes in temperature or excessive moisture) and the presence of highly subjective feelings (such as ease, support and contentment) $[4,5]$.

In addition to facilitating a general sense of wellbeing, the use of comfortable footwear is also considered to have a range of practical advantages, as it may facilitate physical activity [6], enhance sporting performance [7], and reduce the incidence of injury [8]. Therefore, identifying the footwear design, physiological and psychological factors which influence comfort could assist in the development and manufacture of improved footwear

\section{BMC}

(c) The Author(s). 2021 Open Access This article is licensed under a Creative Commons Attribution 4.0 International License, which permits use, sharing, adaptation, distribution and reproduction in any medium or format, as long as you give appropriate credit to the original author(s) and the source, provide a link to the Creative Commons licence, and indicate if changes were made. The images or other third party material in this article are included in the article's Creative Commons licence, unless indicated otherwise in a credit line to the material. If material is not included in the article's Creative Commons licence and your intended use is not permitted by statutory regulation or exceeds the permitted use, you will need to obtain permission directly from the copyright holder. To view a copy of this licence, visit http://creativecommons.org/licenses/by/4.0/ The Creative Commons Public Domain Dedication waiver (http://creativecommons.org/publicdomain/zero/1.0/) applies to the data made available in this article, unless otherwise stated in a credit line to the data. 
for a wide range of population groups, and potentially have both individual and societal benefits. Accordingly, the objective of this study was to provide a narrative synthesis of the research literature pertaining to footwear comfort, including definitions, measurement scales, footwear design features, and physiological and psychological factors.

\section{Methods}

A systematic search was initially conducted in December 2020 and updated in August 2021. The Ovid platform was used to explore MEDLINE (1946 to present), AMED (1985 to present) and Embase (1974 to present) by applying the search string ((footwear or shoe*) and comfort*).mp, limited to human and English language papers. All study designs were considered. Articles addressing comfort of footwear and/or insoles were included, but studies on hosiery, cast walkers or ankle-foot orthoses were excluded. This search was supplemented by a title and abstract search of Footwear Science, as this journal is not indexed in MEDLINE, AMED or Embase. The Ovid search yielded 1131 documents, and after the removal of 328 duplicates, 803 documents were screened by title and abstract. Following title and abstract review there were 120 relevant documents, and after full-text screening 77 documents were included. The Footwear Science search identified 104 documents which was reduced to 24 after full-text review, giving a combined total of 101 documents [1, 3, 5, 7, 9-105] (see Fig. 1). The most relevant manuscripts were selected based on the predetermined subheadings of the review (definitions, measurement scales, footwear design features, and physiological and psychological factors). A narrative synthesis of the findings of these studies was then undertaken.

\section{Results}

\section{Characteristics of included studies}

Most studies were laboratory-based, repeated measures designs where comfort was measured under different footwear and/or insole conditions [14, 15, 18, 20-23, 25-30, 33, 35-39, 41, 43-48, 50-55, 57, 58, 60-71, 73$79,81-87,89,90,93,97,98,100-105]$, but there were also 13 surveys $[1,3,9-11,16,19,24,40,56,88,92,96]$, eight clinical trials [12, 34, 42, 49, 59, 94, 95, 99], three qualitative studies $[13,17,91]$ and three reviews $[5,7$, 72 ]. Sample size ranged from 5 to 1524 , and primarily included healthy young adults $[10,14,15,17,18,22,28$, $31,32,35,37,43-46,48,50,53,54,56,58,60,64,67$, 74-76, 78, 79, 83, 88, 90, 101-104], but also children [71, 91], older people $[1,52,63,76]$, participants with medical conditions (such as diabetes [16, 27, 68, 105], rheumatoid arthritis [29], patellofemoral pain [73], plantar fasciitis [99], hallux valgus [93] and non-specific musculoskeletal disorders/symptoms [25, 95]), specific occupational groups (such as military personnel [42, 69, $85,89]$, factory workers $[9,12]$, school teachers [11], kitchen staff [13], hospital staff [13], coal miners [40, 41] and police officers [94]) and sportspeople (such as runners [26, 30, 36, 39, 47, 49, 65, 66, 70, 77, 82, 84, 86, 98], basketball players $[61,62,92,100]$, soccer players [38, 87, 97], cyclists [20, 21], aerobic dancers [34], skiers [51], rugby players [59], people attending gymnasiums [3], badminton players [55] and tennis players [96]).

\section{Definitions of comfort}

No studies provided a specific definition of comfort, although four studies were designed to explore how comfort is conceptualised. Alcantara et al. [10] developed a list of 74 adjectives related to footwear design and manufacture and asked 67 people to evaluate 36 shoes using these adjectives on a 5-point scale. Principal components analysis demonstrated that perception of casual footwear could be described on the basis of 20 independent concepts, two of which pertained to comfort. The first was characterised as 'pure comfort' and included the positive adjectives good fitting, soft, comfortable, flexible, light, relaxing, smooth, and the negative adjectives rough, hard, strong, heavy, rigid, and robust. The second was characterised as 'thermal comfort' and included the positive adjectives fresh, light, breathable, and the negative adjectives hot, heavy, and safe. Similar findings were reported in a qualitative study of footwear comfort perceptions of standing workers by Anderson et al. [13], who found that positive adjectives used were cushioning, arch support/contour, breathability/ventilation and negative adjectives used were hardness, heaviness and heat. A study of younger women's perceptions of dress shoes identified ten criteria which differentiated between comfortable and uncomfortable shoes, the strongest being absence of pain, feeling, sound, and texture [17]. Finally, in a qualitative study of children, the adjectives soft and padding were most frequently used to describe comfortable shoes, while hard, tight, loose and heavy were used to describe uncomfortable shoes [91].

\section{Comfort measurement scales}

A wide range of measurement tools have been used to quantify comfort, including simple dichotomous responses [11, 12, 29, 94], ranking footwear conditions in order of preference $[14,31-33,36,47,48,52,60,63-65$, 76, 77, 79, 81], 4-point [42, 80], 5-point [37, 40, 45, 58, 70, 76, 97], 6-point [59], 7-point [47, 64, 79, 87], 9-point [57] and 12-point [41] Likert scales, 10-point numerical rating scales [43, 78], and $100 \mathrm{~mm}[15,16,18-21,27,28$, $30,35,39,48,49,53,56,63-65,67,68,71,73,74,77$, $79,82,85,89,90,93,99,104,105], 150 \mathrm{~mm}[22,25,26$, $36,46,50,55,61,62,66,69,75,83,84,98,100]$ and 


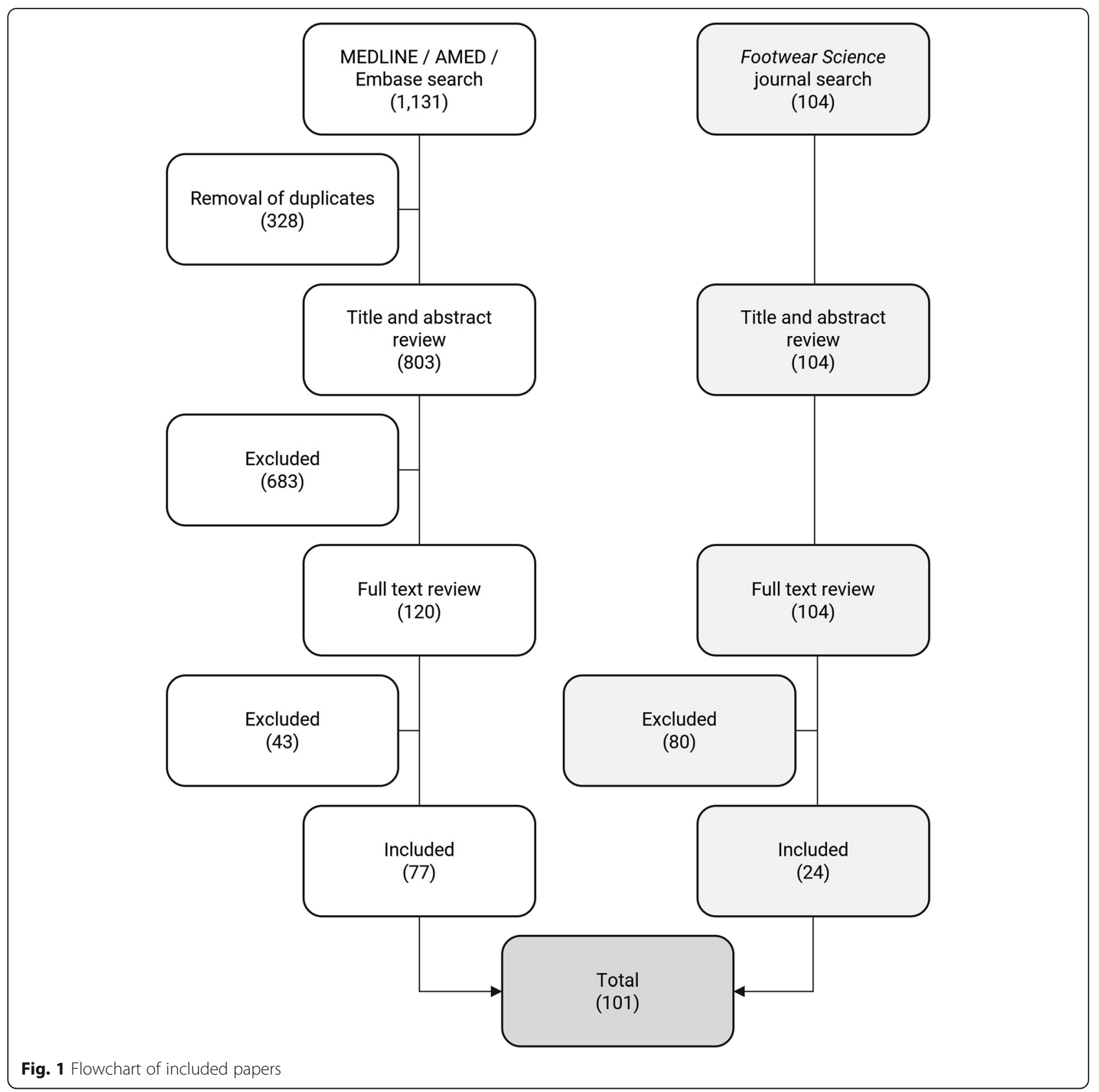

$170 \mathrm{~mm}$ [44] visual analog scales. The anchor statements indicating the lowest possible comfort score included 'not comfortable at all' [19-22, 25, 26, 30, 39, 49, 50, 53, $55,56,61-65,73,79,82-85,89,93]$, 'very uncomfortable' [27, 28, 40, 41, 45, 46, 58, 68, 74, 78, 79, 98], 'least comfortable' [44, 76, 80, 90], 'extremely uncomfortable' $[48,59,89]$, 'not comfortable' $[71,75]$, 'not at all comfortable' $[15,18]$, 'not acceptable' [37, 70], 'totally disagree' [10], 'least comfortable imaginable' [35], 'not satisfactory' [42], 'very bad comfort' [43], 'very, very low' [47], 'minimum comfort' [69], 'maximal pain/discomfort' [99], 'not very comfortable' [100], 'completely uncomfortable' [104], 'extremely bad' [57] and 'unbearable discomfort' [87]. The anchor statements indicating the highest possible comfort score included 'most comfortable imaginable' $[19-22,25,26,30,35,39,46,50,53$, $56,61,63,65,73,79,82-84]$, 'very comfortable' [18, 27, $28,40,41,49,58,68,71,74,75,78,79,98,100]$, 'most comfortable' [44, 55, 62, 76, 80, 85, 90], 'extremely comfortable' [48, 59, 87], 'just right' [37, 70], 'totally agree' [10], 'very much' [15], 'excellent' [42], 'very good comfort' [43], 'not at all uncomfortable' [45], 'very, very high' [47], 'maximum comfort' [69], 'maximal comfortable' [64], 'no pain/discomfort' [99], 'completely comfortable' 
[104], 'most conceivable comfort' [93] and 'extremely good' [57]. Most studies documented an overall comfort score for the whole foot/shoe, while others reported separate comfort scores for specific regions of the foot/shoe $[19,21,22,36,57,59,64,66,71,73,75,83,87,104]$. The vast majority of tools considered comfort to be a unidimensional construct, although some incorporated additional perceptual components including in-shoe 'climate' [55], thermal comfort [51, 67, 103], dampness [67] and air permeability [67].

Seven studies specifically addressed the psychometric properties of comfort scales. Mündermann et al. [83] assessed the reliability of $150 \mathrm{~mm}$ visual analog scales documenting comfort pertaining to forefoot cushioning, heel cushioning, arch height, heel cup fit, shoe heel width, shoe forefoot width, and shoe length in runners wearing standardised running footwear with four inserts of differing hardness. Overall, intra-test repeatability was high (intraclass correlation coefficient [ICC] 0.80 and improved with four to six repeated sessions, although it was noted that some participants reported highly variable comfort ratings. A subsequent study by these authors demonstrated consistency of scores using this scale with repeated sessions over 3 weeks [84], and Lam et al. [62] confirmed the reliability of the same $150 \mathrm{~mm}$ visual analog scale in basketball players (ICCs from 0.61 to 0.80 ). Mills et al. [79] compared the reliability of documenting comfort (overall, cushioning of the forefoot, arch and heel, and support of the arch and heel) in participants wearing their usual footwear and four different inserts using $100 \mathrm{~mm}$ visual analog scales, 7-point Likert scales and ranking, and found that ranking was the most reliable measure, followed by the visual analog scales and Likert scales. Similarly, Lindorfer et al. [64] assessed 30 runners over six repeated sessions, and found that ranking provided the highest reliability (Pearson's $r=$ $0.07)$, followed by a $100 \mathrm{~mm}$ visual analog scale $(r=0.67)$ and 7-point Likert scale $(r=0.63)$. More recently, Bishop et al. [19] reported a detailed psychometric evaluation of a new running shoe comfort assessment tool incorporating four components measured with a $100 \mathrm{~mm}$ visual analog scale (heel cushioning, forefoot cushioning, shoe stability, forefoot flexibility and an overall comfort score). Reliability of the overall score was excellent (ICC 0.88 ) and good for each of the component scores (ICC $>0.70$ ).

In contrast to these positive findings, Hoerzer et al. [50] examined intra-rater reliability of $150 \mathrm{~mm}$ visual analog scales and dichotomous (yes/no) ratings of insole comfort, and found that less than a third of participants provided reliable scores across the two sessions. These findings suggest that psychological factors, such as mood, may influence the perception of comfort and that documenting a mean score across multiple sessions may be necessary to obtain acceptable reliability. Furthermore, a recent systematic review of comfort scales by Matthias et al. [72] demonstrated that few studies explicitly evaluated validity, and many exhibited methodological bias, such as lack of participant and assessor blinding.

\section{Footwear design features associated with comfort Fit}

Three studies explored the effect of footwear fit on comfort. Miller et al. [78] evaluated associations between foot anthropometric measurements and comfort while wearing three different running shoes, and found that a range of measurements (particularly related to shoe fit in the forefoot and toes) influenced comfort perceptions. However, these associations varied across the three styles, suggesting that fit may differentially influence comfort depending on other characteristics of the shoe. In the second study, Branthwaite et al. [22] assessed the effect of toe-box constriction on comfort by comparing three toe-box shapes in ballet pumps (round, square and pointed). Although there was no difference in comfort scores, none of the shoes were considered to be comfortable. Most recently, Matthias et al. [71] assessed comfort ratings of children aged 8 to 12 years while wearing school shoes that were appropriately fitted for size, one size too large, and one size too small. The fitted shoes were rated as the most comfortable overall, while the smaller size was rated as too tight in the heel and toe regions.

\section{Midsole cushioning}

Eight studies evaluated perceived comfort while wearing footwear that varied according to midsole cushioning, including running shoes [39, 60, 78, 90, 98], basketball shoes [61], casual shoes [63] and military boots [85]. All but one study [63] reported that participants found the footwear with softer midsole materials to be more comfortable, although Sterzing et al. [95] also demonstrated that the use of harder materials under the forefoot did not negatively affect comfort provided that the material under the rearfoot was soft. However, documentation of midsole cushioning across these studies was inconsistent, with some studies using no objective measures [60, 61, 78] and others reporting either density (which ranged from 0.15 to $0.24 \mathrm{~g} / \mathrm{cm}^{3}$ ) $[39,90]$ or hardness (which ranged from Shore A 25 to 66) [63, 85, 90]. Furthermore, only three of these studies $[61,63,98]$ specifically manipulated midsole cushioning while controlling for other shoe characteristics, making it difficult to attribute differences in comfort to cushioning alone. 


\section{Heel elevation}

Nine studies examined the effects of heel elevation on comfort perception while wearing high-heels $[28,53,54$, $56,101]$, casual shoes $[75,76]$ and running shoes [23, 82]. In the two running shoe studies, heel elevations (i.e., heel-toe drop) ranged from 0 to $15 \mathrm{~mm}$, but no differences in comfort were found during treadmill walking [23] or running [82]. In contrast, significant reductions in comfort were consistently reported in each of the studies examining high-heels $[28,53,54,56]$ and casual shoes $[75,76]$ when heel height was increased by between 45 and $76 \mathrm{~mm}$. However, comfort perception was higher in participants who were habituated to wearing high heels [28], and three studies reported that the discomfort associated with heel elevation could be partly ameliorated by the use of heel cups [56] and arch supports $[53,54,56]$. An interaction between heel height and the sagittal plane angle of the heel seat ('wedge angle') was also reported by Witana et al. [101], who found that comfort while wearing high heels could be optimised by selecting the most appropriate wedge angle for a corresponding heel height.

\section{Weight}

Five studies evaluated the influence of shoe weight on perceived comfort in military boots [85, 89], safety footwear [18], running shoes [60] and basketball shoes [62]. However, only three studies provided objective measurements of shoe weight (ranging from 335 to $800 \mathrm{~g}$ ) [62, $85,89]$ and none controlled for other shoe characteristics. Nevertheless, all reported that the lightest shoe was perceived to be the most comfortable. In addition to the absolute weight of the shoe, the distribution of mass may also be important. Chiu et al. [33] added weights to different locations of casual canvas shoes while keeping the total weight constant, and found that most participants preferred rear-weighted shoes and perceived them to be lighter than when the weights were added distally.

\section{Sole flexibility/bending stiffness}

Four studies examined the effect of sole flexibility on comfort: two in running shoes $[37,78]$, one in coal mining boots [41], and one in people with diabetes [105]. In running, comfort related to sole flexibility may depend on running speed. Miller et al. [78] compared comfort while standing, walking and running in participants wearing three different commercially-available running shoes, and found that although comfort ratings differed according to the activity, the most comfortable shoe on average was the most flexible. However, Day et al. [37] tested participants in shoes with and without carbon fibre plates and found that participants preferred the standard shoe when running at $14 \mathrm{~km} / \mathrm{h}$, but the stiffer shoe at $17 \mathrm{~km} / \mathrm{h}$. The coal mining boot study assessed comfort when coal miners wore two standard boots (one with a stiff shaft and one with a flexible shaft), and each boot was then modified to create a more flexible sole by cutting slits across the sole at the level of the metatarsophalangeal joints. Although most participants preferred the boot with a flexible shaft combined with a stiff (unmodified) sole, there was large variability in the comfort scores and no significant effect among the different boot types [41]. Finally, Zwaferink et al. [105] found that adding a $3 \mathrm{~mm}$ carbon-fibre stiffening insert to extra-depth shoes in people at risk of foot ulceration resulted in lower plantar pressures, but had no detrimental effect on comfort.

\section{Midsole geometry}

Seven studies evaluated the influence of various aspects of midsole geometry on comfort, including offloading/ rocker-sole footwear (in healthy individuals [43, 66], older people [52], people with diabetes [27, 68] and people with rheumatoid arthritis [29]), and the application of lateral wedges to footwear for the treatment of knee osteoarthritis [44]. In the offloading footwear studies, rocker-sole shoes were perceived to be more comfortable than standard footwear [29] or forefoot offloading shoes (i.e., shoes with no ground contact at the forefoot designed to avoid toe-off) [27, 43], and rigid rocker-sole shoes more comfortable than semirigid rocker-sole shoes [68]. However, no substantial differences in comfort were found across three different heel curvature designs (short-parallel, long-parallel and oblique) in running shoes [66], adding foam to the plantar midfoot region of the outersole [52], or following the addition of a small (2 degree) lateral heel wedge designed to alter knee joint moments when walking [44].

\section{Outsole geometry}

Three studies evaluated the effect of outsole geometry on comfort [38, 59, 87]. In soccer boots, de Clerq et al. [38] assessed the effect of various stud configurations on comfort when performing cutting manoeuvres, and found that the sole design with the least number of studs was the most comfortable. Kryger et al. [87] compared two soccer boot designs that varied according to stud shape, upper material and boot mass, and found that the most comfortable boot generated lower pressures under the first and fifth metatarsal heads. Similarly, in rugby, Kinchington et al. found that hybrid turf shoes were more comfortable than studded boots [59].

\section{Lacing}

Two studies evaluated the effect of lacing on comfort. Dobson et al. [40] reported lace-up boots to be more comfortable than slip-on boots in coal miners, while Hagen et al. [58] compared different styles of lacing in 
seven-eyelet running shoes, and found that comfort varied according to the number of eyelets laced and how tightly the laces were tied. The most comfortable technique involved the use of three eyelets laced while keeping the upper two eyelets unlaced, although this was perceived to be less stable and was associated with higher pronation velocity while running compared to tightly lacing all eyelets.

\section{Upper material}

Four studies demonstrated that shoes with more compliant upper materials may be preferable. Jordan et al. [58] compared three styles of casual footwear and found that shoes generating lower pressures on the dorsum of the foot were perceived as more comfortable, while Melvin et al. [75] found that shoes constructed from soft suede were more comfortable than shoes constructed from a stiffer leather upper. In soccer boots, Sterzing et al. [97] found that despite two models having identical stud configurations, the model with the softer heel counter was perceived to be more comfortable. Finally, Saeedi et al. [93] evaluated people with hallux valgus wearing their own shoes, shoes with a round toe-box and shoes with a stretchable fabric upper, and found that the shoes with the stretchable upper generated lower toe pressures and were perceived to be the most comfortable.

\section{Shoe microclimate}

Four studies evaluated the influence of shoe microclimate (i.e., temperature, moisture and ventilation characteristics) on comfort, generally in the context of footwear worn in cold environments (such as trekking boots [15], safety boots [45] and ski boots [51]), but also in sandals used in combination with footwarmers indoors [103]. The findings of these studies were inconsistent, in that higher temperatures were found to be associated with improved comfort perceptions in ski boots [51], when adding insulation and toecaps to safety boots [45] and in indoor sandals [103], but lower temperatures were found to be more comfortable in trekking boots [15]. Likely explanations for this inconsistency are the range of ambient temperatures each study was performed in (which varied from -6.8 to $23.3^{\circ} \mathrm{C}$ ) and different methods for measuring inshoe temperature. The role of moisture and ventilation has been less studied and is inherently difficult to delineate from temperature effects. However, the study of trekking boots by Arezes et al. [15] found moisture retention to be of secondary importance to temperature in determining comfort levels.

\section{Insoles}

Twenty-six studies have been conducted to assess the effects of insoles on footwear comfort. However, it is difficult to draw clear conclusions from the available literature due to the variation in populations studied and wide range of insole designs used. Broadly, the evidence suggests that the addition of insoles improves footwear comfort in casual footwear [95], factory footwear [12], running shoes $[25,26,49,84]$, high heels $[53,54]$ and police boots [94]. However, no significant improvements in comfort have been reported when adding flat cushioning insoles to walking shoes [74] or running shoes [86], or contoured insoles to cycling shoes [20]. Furthermore, the effect of insoles on footwear comfort is influenced by the fit of the shoe, as it has been observed that insoles may decrease comfort if they make the shoe too tight [34].

Studies comparing different insole designs have generally found that softer, more flexible insoles are perceived as more comfortable (in casual footwear [99], running shoes $[31,67,80]$ and military footwear $[42,69])$. However, comfort perceptions related to insole hardness may vary according to an individual's occupation, as Anderson et al. [14] have reported that people standing for long periods at work prefer soft materials under the heel and forefoot but firmer materials under the arch. The influence of insole shape is uncertain, with studies reporting flat insoles to be more comfortable than contoured [48], contoured more comfortable than flat $[69,100]$, or no difference between the two [73]. Furthermore, the effect of insole customisation is unclear. Fully customised orthoses have been reported to be more comfortable than semi-customised insoles in runners [36], while reductions in comfort have been observed with the addition of anterior wedges when performing a load lifting task [46] and lateral forefoot posting when cycling [21].

\section{Wear time}

One study assessed the effect of repeated wear on comfort while wearing badminton shoes [55]. Badminton players performed direction change manoeuvres while wearing new shoes and then the same shoes after $96 \mathrm{~h}$ of wear (6, 2-h training sessions per week for 8 weeks). The worn shoes were perceived to be significantly less comfortable in relation to in-shoe climate, medio-lateral stability, and overall fit, although performance in direction change manoeuvres was not adversely affected.

\section{Physiological and psychological factors associated with comfort \\ Sex}

Two studies assessed sex differences in comfort perception in running shoes, with inconsistent findings [57, 60]. Kong et al. [60] instructed healthy men and women to walk and run in three types of footwear (cushioning, lightweight and stability) and asked them to select the model that they found most comfortable. No differences 
were noted between walking and running, but women were four times more likely to select the lightweight shoe compared to men, which the authors attributed to women weighing less and therefore preferring a shoe with less metabolic energy cost. In contrast, Isherwood et al. [57] analysed running biomechanics in men and women wearing the same running shoe model, and despite noting several sex-related differences in kinematics and kinetics, found no difference in perception of cushioning, stability, or overall comfort.

\section{Foot-related factors}

Four studies have evaluated associations between foot characteristics and comfort, specifically addressing foot alignment [14, 78, 104] and tactile sensitivity [81]. In relation to arch height, Zifchock et al. [104] compared comfort ratings while wearing custom and semi-custom orthoses, and found that participants with high arches reported greater arch and heel comfort in the semicustom device which provided less rearfoot control when walking, while Anderson et al. [14] assessed perceptions of nine different insoles which varied according to the hardness of the heel, midfoot and forefoot in participants working in occupations that require prolonged standing, and found that those with lower arched feet preferred insoles with harder material in the midfoot. Miller et al. [78] compared comfort perceptions when walking and running in three shoes that varied in relation to stiffness, cushioning and shape, and found that heel eversion angle was negatively associated with comfort in the stiffer, harder soled shoe. Finally, Mills et al. [81] compared minimalist and cushioned shoes during running and found that individuals who ranked the cushioned shoe as most comfortable demonstrated higher sensitivity to mechanical pain at their heel and midfoot.

\section{Perceptual factors}

Three studies explored the effects of perceptual factors on footwear comfort. Chamb et al. [30] evaluated running biomechanics on a treadmill under two footwear conditions (shoe A and B). Identical running shoes were used in both conditions, but shoe B was described to be the "latest model designed to maximize comfort" and more expensive than shoe A. Although no differences in running biomechanics were evident, runners rated shoe $\mathrm{B}$ as significantly more comfortable than shoe A, demonstrating that comfort ratings can be biased by marketing and perceived quality related to cost. However, runners' perceptions of comfort do not appear to be strongly associated with actual cost of shoes. Clinghan et al. [35] measured plantar pressures, comfort scores and perceived cost of shoes at three price ranges, but found no significant associations, suggesting that comfort is highly subjective and based on individual preferences. Finally, in basketball players, Wang et al. [100] evaluated comfort perceptions when performing drop landings while wearing insoles that differed according to colour and contour, and found that red insoles were perceived to be more comfortable than white insoles with the same contour.

\section{Discussion}

The objective of this study was to provide a summary and critique of the research literature pertaining to footwear comfort. Overall, the available evidence is highly fragmented and incorporates a wide range of study designs, participants, and assessment approaches, making it challenging to draw strong conclusions or implications for clinical practice. It is evident that footwear comfort is a complex and multifaceted concept, that perceptions of comfort are highly subjective, and that comfort is influenced not only by structural and functional aspects of shoe design, but also anatomical and physiological differences between individuals and the unique requirements of the occupational or sporting activity being performed. Nevertheless, there is sufficient uniformity in key findings to provide some broad recommendations as to how comfort should be assessed and what constitutes a comfortable shoe. A summary of the key factors influencing comfort are shown in Fig. 2.

Somewhat surprisingly, no studies specifically defined comfort, and a wide range of assessment scales were used. The anchor statements were also highly variable and conceptually inconsistent. For example, some scales considered the absence of comfort as the worst state (with 'not comfortable' as the anchor statement), whereas other scales were bidirectional and used anchors such as 'extremely uncomfortable' for the lowest possible scores. From a psychometric perspective, it is unlikely that 'not comfortable' and 'extremely uncomfortable' represent the same construct, so making comparisons between studies using different scales is problematic. Nevertheless, the most widely used overall comfort tools (100 mm or $150 \mathrm{~mm}$ visual analog scales) demonstrated moderate to high reliability and could therefore be recommended for future use. However, as suggested by Matthias et al. [72], it would be advisable to evaluate reliability within each individual study's sample population, and to conceal the external appearance of the shoe to avoid bias introduced by participant's perceptions of footwear aesthetics.

Despite the wide range of occupational and sporting groups evaluated in these studies and their different footwear requirements, it would appear that there are some generic design principles that constitute a comfortable shoe. First, a comfortable shoe is one that fits the foot appropriately, although it needs to be recognised 

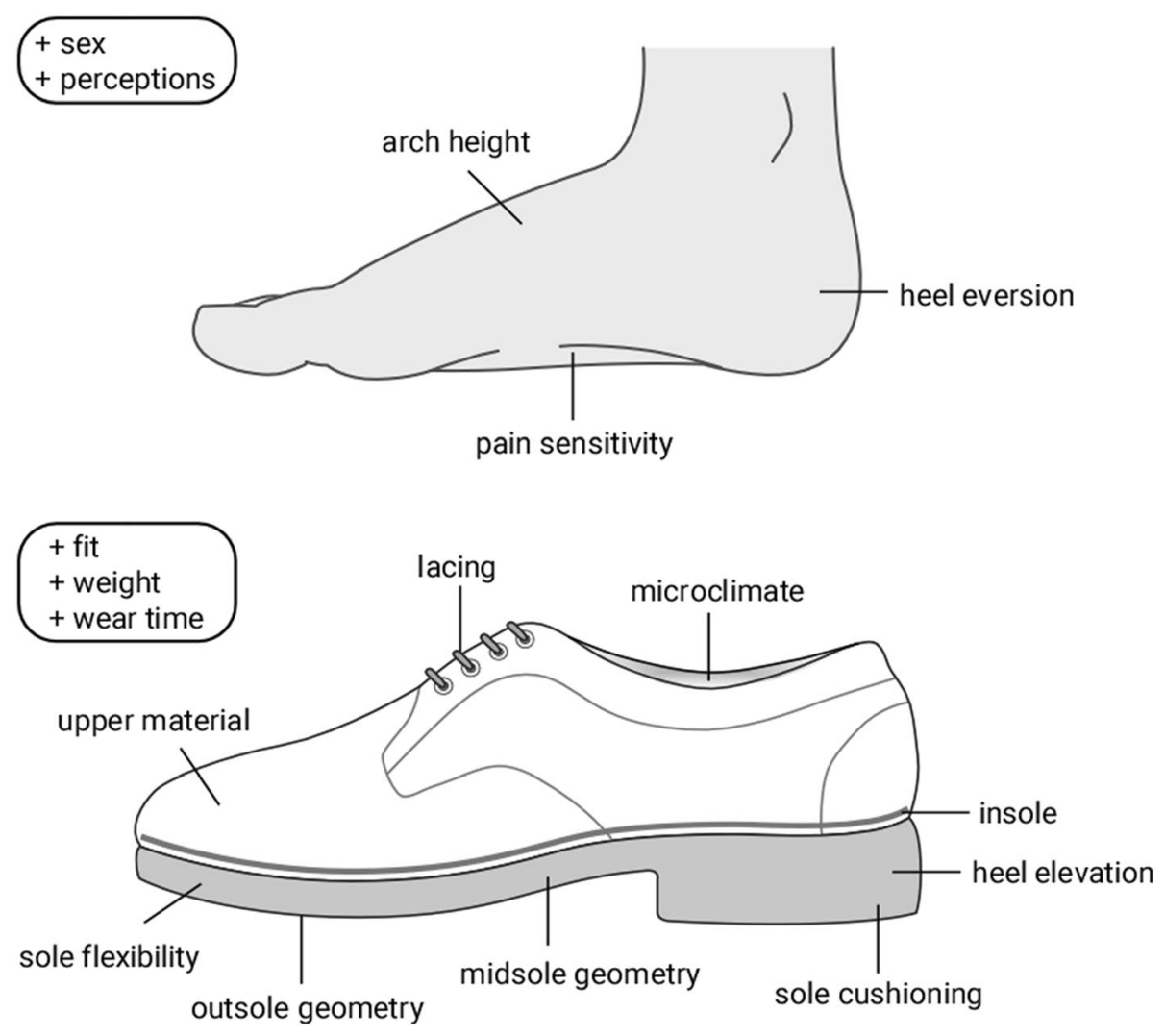

Fig. 2 Summary of factors associated with footwear comfort

that some very specific situations may require excessively tight shoes (e.g., ballet [106] and rock-climbing [107]). Second, softer and more compliant materials are generally regarded as being more comfortable than harder materials in the upper, midsole and insole. Third, with the exception of individuals who have become habituated to high heels over long periods of use [28], lower heel elevation is generally associated with greater perceived comfort. Fourth, the available evidence suggests that lightweight shoes are generally preferred over heavier shoes. Finally, curved rocker-soles appear to be beneficial for comfort compared to flat soles in a range of population groups.

Less consistency was observed for sole flexibility, inshoe temperature and insoles. The most likely explanation for this is that the effects of these features on comfort are more specific to the population, setting and task. For example, while runners generally prefer a flexible sole, coal miners prefer a more rigid sole, presumably as this facilitates more comfortable ambulation on uneven or unstable terrain. Similarly, while relatively lower inshoe temperatures are generally perceived as more comfortable under routine climatic conditions (generally temperatures of 5 to $25^{\circ} \mathrm{C}$ ) [5], higher in-shoe temperatures are preferred in the context of lower ambient temperatures, such as when wearing trekking or ski boots. Finally, although the evidence broadly indicates that the addition of soft insoles to shoes generally improves comfort, the wide array of insole designs (materials, contour, posting and wedging) makes it difficult to reach definitive conclusions.

Few studies examined how comfort ratings are influenced by the interaction between footwear and individual characteristics of the wearer. Given that comfort is a complex neurophysiological and psychological construct, it is likely that variability in an individual's body mass, skeletal alignment, joint range of motion, gait pattern, tactile sensitivity, pain perceptions and aesthetic preferences will influence whether they perceive a particular shoe to be comfortable. While the available evidence suggests that foot structure, function and pain sensitivity may influence insole contour and sole hardness preferences, further research is required to optimise the identification of footwear features that are most suitable for an individual's anatomical and physiological characteristics.

It is worth noting that while comfort is one of the key considerations when selecting footwear, other factors, such as performance and injury risk, also need to be considered and that these requirements are not necessarily compatible. For example, in running shoes, leaving 
the top two eyelets unlaced is perceived as the most comfortable but also least stable lacing technique, and results in higher pronation velocity which may increase the risk of injury [58]. Similarly, while older people may find shoes with softer midsole materials to be more comfortable, there is evidence that excessively soft midsoles may be detrimental to balance and therefore increase the risk of falls [108]. Clearly, comfort is not the only requirement of footwear, and in some circumstances, comfort may need to be compromised to ensure other needs are met. This is particularly true for some types of occupational footwear, where important safety features (such as steel toe caps, rigid upper materials, and non-slip soles) may be detrimental to comfort but are essential for the prevention of workplace injury.

The findings of this review need to be interpreted in the context of several key limitations in the available literature. Firstly, a wide range of comfort measurement tools were used, so comparisons between studies is inherently problematic. Secondly, few studies specifically manipulated individual footwear design features while controlling for other characteristics, making it difficult to attribute differences in comfort to each individual feature. Finally, although we were able to draw some general conclusions regarding factors that influence comfort, it is likely that these factors influence comfort in different ways depending on the specific requirements of the setting and the activity being performed.

In summary, this paper has provided an overview of how footwear comfort is conceptualised and evaluated and has examined the footwear design features and individual characteristics that influence the perception of footwear comfort. Although the literature is fragmented and often inconsistent, it can be concluded that (i) simple visual analog scales may provide a reliable (albeit unidimensional) assessment of comfort, (ii) well-fitted, lightweight shoes with soft midsoles and curved rockersoles are generally perceived to be most comfortable, and (iii) the influence of sole flexibility, in-shoe temperature and insoles is less clear and likely to be more specific to the population, setting and task. Suggested improvements and directions for future research include (i) specifically manipulating individual design features while controlling for other shoe characteristics, (ii) exploring the influence of shoe microclimate in greater detail, and (iii) examining the interaction between footwear features and individual physiological attributes.

\section{Acknowledgements}

HBM is currently a National Health and Medical Research Council Senior Research Fellow (ID: 1135995). DRB is Associate Editor of Journal of Foot and Ankle Research. It is journal policy to remove editors from the peer review processes for papers they have co-authored.

\section{Authors' contributions}

HBM conceptualised the review, conducted the literature search and drafted the initial manuscript. Both HBM and DRB contributed to interpretation of study findings, critically drafted the manuscript, and approved the final manuscript for publication.

Funding

Not applicable.

Availability of data and materials

Not applicable.

\section{Declarations}

Ethics approval and consent to participate

Not applicable.

Consent for publication

Not applicable.

Competing interests

None to declare.

Received: 17 October 2021 Accepted: 15 November 2021

Published online: 07 December 2021

\section{References}

1. Munro B, Steele J. Household-shoe wearing and purchasing habits. A survey of people aged 65 years and older. J Am Podiatr Med Assoc. 1999;89(10): 506-14.

2. Janson D, Newman ST, Dhokia V. Safety footwear: a survey of end-users. Appl Ergon. 2021;92:103333.

3. Apps C, Liu H, Pykett J, Sterzing T. Gym training shoe requirements in China and England. Footwear Sci. 2015;7(1):51-62.

4. Pearson EJM. Comfort and its measurement - a literature review. Disabil Rehabil Assist Technol. 2009;4(5):301-10.

5. Kuklane K. Protection of feet in cold exposure. Ind Health. 2009;47(3):242-53.

6. Shields N, Lim P, Wollersheim D, Nikolopoulos N, Barrett J, Evans A, et al. Do foot posture, deformity, and footwear fit influence physical activity levels in children with Down syndrome? A prospective cohort study. J Intellect Develop Disabil. 2017:42(4):332-8.

7. Hoitz F, Mohr M, Asmussen M, Lam W-K, Nigg S, Nigg B. The effects of systematically altered footwear features on biomechanics, injury, performance, and preference in runners of different skill level: a systematic review. Footwear Sci. 2020;12(3):193-215.

8. Mundermann A, Stefanyshyn DJ, Nigg BM. Relationship between footwear comfort of shoe inserts and anthropometric and sensory factors. Med Sci Sports Exerc. 2001;33(11):1939-45.

9. Akbar-Khanzadeh F. Factors contributing to discomfort or dissatisfaction as a result of wearing personal protective equipment. J Hum Ergol. 1998;27(12):70-5.

10. Alcantara E, Artacho MA, Gonzalez JC, Garcia AC. Application of product semantics to footwear design. Part I - identification of footwear semantic space applying diferential semantics. Int J Ind Ergon. 2005;35(8):713-25.

11. Alias AN, Karuppiah K, How V, Perumal V, Tamrin SBM, Naeini HS. The perception on school footwear comfort among primary school female teachers in Terengganu. Int J Pharmaceut Res. 2020;12(3):2085-93.

12. Almeida JS, Vanderlei FM, Pastre EC, Martins RA, Padovani CR, Filho GC. Comparison of two types of insoles on musculoskeletal symptoms and plantar pressure distribution in a work environment: a randomized clinical trial. Clin Med Res. 2016;14(2):67-74

13. Anderson J, Williams $A E$, Nester $C$. An explorative qualitative study to determine the footwear needs of workers in standing environments. J Foot Ankle Res. 2017;10:41.

14. Anderson J, Williams AE, Nester C. Development and evaluation of a dual density insole for people standing for long periods of time at work. J Foot Ankle Res. 2020;13(1):42.

15. Arezes PM, Neves MM, Teixeira SF, Leao CP, Cunha JL. Testing thermal comfort of trekking boots: An objective and subjective evaluation. Appl Ergon. 2013:44(4):557-65. 
16. Arts ML, de Haart M, Bus SA, Bakker JP, Hacking HG, Nollet F. Perceived usability and use of custom-made footwear in diabetic patients at high risk for foot ulceration. J Rehabil Med. 2014;46(4):357-62.

17. Au EY, Goonetilleke RS. A qualitative study on the comfort and fit of ladies' dress shoes. Appl Ergon. 2007;38(6):687-96.

18. Bagheri ZS, Patel N, Li Y, Morrone K, Fernie G, Dutta T: Slip resistance and wearability of safety footwear used on icy surfaces for outdoor municipal workers. Work (Reading, Mass) 2019, 62(1):37-47.

19. Bishop C, Buckley JD, Esterman AE, Arnold JB. The running shoe comfort assessment tool (RUN-CAT): development and evaluation of a new multiitem assessment tool for evaluating the comfort of running footwear. J Sports Sci. 2020;38(18):2100-7.

20. Bousie JA, Blanch P, McPoil TG, Vicenzino B. Contoured in-shoe foot orthoses increase mid-foot plantar contact area when compared with a flat insert during cycling. J Sci Med Sport. 2013;16(1):60-4.

21. Bousie JA, Blanch P, McPoil TG, Vicenzino B. Hardness and posting of foot orthoses modify plantar contact area, plantar pressure, and perceived comfort when cycling. J Sci Med Sport. 2018;21(7):691-6.

22. Branthwaite $H$, Chockalingam N, Greenhalgh $A$, Chatzistergos $P$. The impact of different footwear characteristics, of a ballet flat pump, on centre of pressure progression and perceived comfort. Foot (Edinb.) 2014;24(3):11622.

23. Brauner T, Hooper S, Horstmann T, Wearing S. Effects of footwear and heel elevation on tensile load in the Achilles tendon during treadmill walking. Footwear Sci. 2018;10(1):39-46.

24. Brenton-Rule A, Dalbeth N, Edwards NL, Rome K. Experience of finding footwear and factors contributing to footwear choice in people with gout: a mixed methods study using a web-based survey. J Foot Ankle Res. 2019; $12: 3$.

25. Burke JR. Effects of footwear comfort perception on the neuromuscular control of balance. Int J Neurosci. 2012;122(4):209-20.

26. Burke JR, Papuga MO. Effects of foot orthotics on running economy: methodological considerations. J Manip Physiol Ther. 2012;35(4):327-36.

27. Bus SA, van Deursen RWM, Kanade RV, Wissink M, Manning EA, van Baal JG, et al. Plantar pressure relief in the diabetic foot using forefoot offloading shoes. Gait Posture. 2009;29(4):618-22

28. Cha YJ. Analysis of differences in the degree of biomechanical adaptation according to habituation to different heel heights. ScientificWorldJournal. 2020;2020:1854313.

29. Cham MB, Ghasemi MS, Forogh B, Sanjari MA, Yeganeh MZ, Eshraghi A. Effect of rocker shoes on pain, disability and activity limitation in patients with rheumatoid arthritis. Prosthet Orthot Int. 2014;38(4):310-5.

30. Chan ZYS, Au IPH, Zhang JH, Ferber R, Shum G, An WW, et al. Effects of deceptive footwear condition on subjective comfort and running biomechanics. Translat Sports Med. 2020;3(3):256-62.

31. Chen $\mathrm{H}$, Nigg BM, De Koning J. Relationship between plantar pressure distribution under the foot and insole comfort. Clin Biomech. 1994;9(6):33541.

32. Chen $\mathrm{H}$, Nigg BM, Hulliger $M$, De Koning J. Influence of sensory input on plantar pressure distribution. Clin Biomech. 1995;10(5):271-4.

33. Chiu H-T, Lin $\mathrm{H}-\mathrm{H}$. A preference test on shoes with varied distributions of masses. Footwear Sci. 2019;11(3):181-9.

34. Clark JE, Scott SG, Mingle M. Viscoelastic shoe insoles: their use in aerobic dancing. Arch Phys Med Rehabil. 1989;70(1):37-40.

35. Clinghan A, Arnold G, Drew T, Cochrane L, Abboud R. Do you get value for money when you buy an expensive pair of running shoes? Br J Sports Med. 2008;42(3):189-93.

36. Davis IS, Zifchock RA, Deleo AT. A comparison of rearfoot motion control and comfort between custom and semicustom foot orthotic devices. J Am Podiatr Med Assoc. 2008;98(5):394-403.

37. Day E, Hahn M. Optimal footwear longitudinal bending stiffness to improve running economy is speed dependent. Footwear Sci. 2020;12(1):3-13.

38. De Clercq D, Debuyck G, Gerlo J, Rambour S, Segers V, Van Caekenberghe I. Cutting performance wearing different studded soccer shoes on dry and wet artificial turf. Footwear Sci. 2014;6(2):81-7.

39. Dinato RC, Ribeiro AP, Butugan MK, Pereira ILR, Onodera AN, Sacco ICN. Biomechanical variables and perception of comfort in running shoes with different cushioning technologies. J Sci Med Sport. 2015;18(1):93-7.

40. Dobson J, Riddiford-Harland D, Bell A, Steele J. Effect of work boot type on work footwear habits, lower limb pain and perceptions of work boot fit and comfort in underground coal miners. Appl Ergon. 2017;60:146-53.
41. Dobson JA, Riddiford-Harland DL, Bell AF, Wegener C, Steele JR. Effect of shaft stiffness and sole flexibility on perceived comfort and the plantar pressures generated when walking on a simulated underground coal mining surface. Appl Ergon. 2020;84:103024.

42. Finestone A, Novack V, Farfel A, Berg A, Amir H, Milgrom C. A prospective study of the effect of foot orthoses composition and fabrication on comfort and the incidence of overuse injuries. Foot Ankle Int. 2004;25(7):462-6.

43. Fuchs MCHW, Hermans MMN, Kars HJJ, Hendriks JGE, van der Steen MC: Plantar pressure distribution and wearing characteristics of three forefoot offloading shoes in healthy adult subjects. Foot (Edinb.) 2020;45:101744.

44. Fukuchi C, Worobets J, Wannop JW, Stefanyshyn D. A small integrated lateral wedge does not alter knee joint moments during walking. Footwear Sci. 2012;4(3):207-12.

45. Gao C, Abeysekera J. The assessment of the integration of slip resistance, thermal insulation and wearability of footwear on icy surfaces. Safety Sci. 2002;40(7-8):613-24.

46. Ghasemi MH, Anbarian M. Immediate effects of using insoles with various wedges on center of pressure indices and comfort rating during load lifting. Appl Ergon. 2020;88:103195.

47. Hagen M, Hennig EM. Effects of different shoe-lacing patterns on the biomechanics of running shoes. J Sports Sci. 2009;27(3):267-75.

48. Hatton AL, Hug F, Brown BCM, Green LP, Hughes JR, King J, et al. A study of the immediate effects of glycerine-filled insoles, contoured prefabricated orthoses and flat insoles on single-leg balance, gait patterns and perceived comfort in healthy adults. J Foot Ankle Res. 2015;8(1):47.

49. Hirschmuller A, Baur H, Muller S, Helwig P, Dickhuth H, Mayer F. Clinical effectiveness of customised sport shoe orthoses for overuse injuries in runners: a randomised controlled study. Br J Sports Med. 2011;45(12):95965.

50. Hoerzer S, Trudeau MB, Edwards WB, Nigg BM. Intra-rater reliability of footwear-related comfort assessments. Footwear Sci. 2016;8(3):155-63.

51. Hofer P, Hasler M, Fauland G, Bechtold T, Nachbauer W. Microclimate in ski boots--temperature, relative humidity, and water absorption. Appl Ergon. 2014;45(3):515-20.

52. Hömme A-K, Hennig EM, Müller C, Ninck C. The influence of two unstable shoe modifications on lower extremity kinetics during walking and postural balance in elderly men. Footwear Sci. 2012;4(2):83-91.

53. Hong $W$, Lee $Y$, Chen $H$, Pei $Y$, Wu C. Influence of heel height and shoe insert on comfort perception and biomechanical performance of young female adults during walking. Foot Ankle Int. 2005;26(12):1042-8.

54. Hong WH, Lee YH, Lin YH, Tang SFT, Chen HC. Effect of shoe heel height and total-contact insert on muscle loading and foot stability while walking. Foot Ankle Int. 2013;34(2):273-81.

55. Hong Y, Lam WK, Wang S, Cheung JT-M. Changes in comfort perception and direction change performance of badminton shoes with extensive usage time. Footwear Sci. 2016;8(1):13-7.

56. Hui $L$, Wei-Hsien $H$. Effects of shoe inserts and heel height on foot pressure, impact force, and perceived comfort during walking. Appl Ergon. 2005;36(3): 355-62.

57. Isherwood J, Wang H, Sterzing T. Running biomechanics and running shoe perception of Chinese men and women. Footwear Sci. 2021;13(1): $55-67$.

58. Jordan C, Bartlett R. Pressure distribution and perceived comfort in casual footwear. Gait Posture. 1995;3(4):215-20.

59. Kinchington M, Ball K, Naughton G. An investigation into the role of a footwear intervention program for professional footballers: An intra-club control and intervention study. Gazz Med Ital. 2012;171(2):143-56.

60. Kong P, Bagdon M. Shoe preference based on subjective comfort for walking and running. J Am Podiatr Med Assoc. 2010;100(6):456-62.

61. Lam WK, Qu Y, Yang F, Cheung RTH: Do rotational shear-cushioning shoes influence horizontal ground reaction forces and perceived comfort during basketball cutting maneuvers? PeerJ 2017, 2017(11).

62. Lam WK, Sterzing T, Cheung JT-M. Reliability of a basketball specific testing protocol for footwear fit and comfort perception. Footwear Sci. 2011;3(3): $151-8$.

63. Lane T, Landorf K, Bonanno D, Raspovic A, Menz H. Effects of shoe sole hardness on plantar pressure and comfort in older people with forefoot pain. Gait Posture. 2014;39(1):247-51.

64. Lindorfer J, Kroll J, Schwameder H. Comfort assessment of running footwear: does assessment type affect inter-session reliability? Eur J Sport Sci. 2019;19(2):177-85 
65. Lindorfer J, Kroll J, Schwameder H. Does enhanced footwear comfort affect oxygen consumption and running biomechanics? Eur J Sport Sci. 2020; 20(4):468-76.

66. Liu ZL, Lam WK, Zhang X, Vanwanseele B, Liu H. Influence of heel design on lower extremity biomechanics and comfort perception in overground running. J Sports Sci. 2020:1-7.

67. Lo WT, Wong DP, Yick KL, Ng SP, Yip J. The biomechanical effects and perceived comfort of textile-fabricated insoles during straight line walking. Prosthet Orthot Int. 2018;42(2):153-62.

68. Lopez-Moral M, Molines-Barroso RJ, Alvaro-Afonso FJ, Uccioli L, Senneville E, Lazaro-Martinez $\mathrm{JL}$. Importance of footwear outsole rigidity in improving spatiotemporal parameters in patients with diabetes and previous forefoot ulcerations. J Clin Med. 2020;9(4):907.

69. Lullini G, Giangrande A, Caravaggi P, Leardini A, Berti L. Functional evaluation of a shock absorbing insole during military training in a group of soldiers: a pilot study. Mil Med. 2020;185(5-6):e643-8.

70. Luo G, Stergiou P, Worobets J, Nigg B, Stefanyshyn D. Improved footwear comfort reduces oxygen consumption during running. Footwear Sci. 2009; 1(1):25-9.

71. Matthias E, Banwell HA, Arnold JB. Children's school footwear: the impact of fit on foot function, comfort and jump performance in children aged 8 to 12 years. Gait Posture. 2021;87:87-94.

72. Matthias EC, Banwell HA, Arnold JB. Methods for assessing footwear comfort: a systematic review. Footwear Sci. 2021;13(3):255-74.

73. MCPoil TG, Vicenzino B, Cornwall MW. Effect of foot orthoses contour on pain perception in individuals with patellofemoral pain. J Am Podiatr Med Assoc. 2011;101(1):7-16.

74. Melia G, Siegkas P, Levick J, Apps C. Insoles of uniform softer material reduced plantar pressure compared to dual-material insoles during regular and loaded gait. Appl Ergon. 2021;91:103298.

75. Melvin JMA, Price C, Preece S, Nester C, Howard D. An investigation into the effects of, and interaction between, heel height and shoe upper stiffness on plantar pressure and comfort. Footwear Sci. 2019;11(1):25-34.

76. Menant JC, Perry SD, Steele JR, Menz HB, Munro BJ, Lord SR. Effects of shoe characteristics on dynamic stability when walking on even and uneven surfaces in young and older people. Arch Phys Med Rehabil. 2008;89(10): 1970-6

77. Meyer C, Mohr M, Falbriard M, Nigg SR, Nigg BM. Influence of footwear comfort on the variability of running kinematics. Footwear Sci. 2018;10(1): 29-38.

78. Miller J, Nigg B, Liu W, Stefanyshyn D, Nurse M. Influence of foot, leg and shoe characteristics on subjective comfort. Foot Ankle Int. 2000;21(9):75967.

79. Mills K, Blanch P, Vicenzino B. Identifying clinically meaningful tools for measuring comfort perception of footwear. Med Sci Sports Exerc. 2010; 42(10):1966-71.

80. Mills K, Blanch P, Vicenzino B. Comfort and midfoot mobility rather than orthosis hardness or contouring influence their immediate effects on lower limb function in patients with anterior knee pain. Clin Biomech. 2012;27(2): 202-8.

81. Mills KAG, Collins NJ, Vicenzino B. The relationship between immediate comfort and plantar foot sensitivity during running in cushioned versus minimal shoes. Footwear Sci. 2018;10(1):21-7.

82. Mo S, Lam W-K, Ching ECK, Chan ZYS, Zhang JH, Cheung RTH. Effects of heel-toe drop on running biomechanics and perceived comfort of rearfoot strikers in standard cushioned running shoes. Footwear Sci. 2020;12(2):91-9.

83. Mundermann A, Nigg B, Stefanyshyn D, Humble R. Development of a reliable method to assess footwear comfort during running. Gait Posture. 2002;16(1):38-45.

84. Mundermann A, Nigg BM, Humble RN, Stefanyshyn DJ. Consistent immediate effects of foot Orthoses on comfort and lower extremity kinematics, kinetics, and muscle activity. J Appl Biomech. 2004;20(1):71-84.

85. Muniz A, Bini R. Shock attenuation characteristics of three different military boots during gait. Gait Posture. 2017;58:59-65.

86. O'Leary K, Anderson VK, Heiderscheit B. Effect of cushioned insoles on impact forces during running. J Am Podiatr Med Assoc. 2008;98(1):36-41.

87. Okholm Kryger K, Mutamba K, Mitchell S, Miller SC, Forrester S. Physical performance and perception of foot discomfort during a soccer-specific match simulation. A comparison of football boots. J Sports Sci. 2021;39(9): 1046-54.
88. Ozdinc S, Unsar S, Akgun Kostak M. Musculoskeletal problems and attitudes towards footwear among university students. J Back Musculoskelet Rehabil. 2019;32(1):141-7.

89. Pace MT, Green JM, Killen LG, Swain JC, Chander H, Simpson JD, et al. Minimalist style boot improves running but not walking economy in trained men. Ergonomics. 2020;63(10):1329-35.

90. Peng P, Ding S, Wang Z, Zhang Y, Pan J. Acute effect of engineered thermoplastic polyurethane elastomer knockoff running footwear on foot loading and comfort during heel-to-toe running. Gait Posture. 2020;79:1116.

91. Price C, Skidmore S, Ratcliffe J, Williams A. Children should be seen and also heard: an explorative qualitative study into the influences on children's choice of footwear, their perception of comfort and the language they use to describe footwear experiences. J Foot Ankle Res. 2021;14(1):49.

92. Punjabi M, Bagchi A: Brand loyalty and shoe attributes preference of Indian national basketball players. Ann Trop Med Public Health 2020;23:17.

93. Saeedi H, Azadinia F, Jalali M, Bagheripour B, Ronasi P, Ershadi FS: Shoes with elastic upper vs. shoes with a round toe box for perceived comfort and interdigital forefoot pressure in patients with hallux valgus deformity. Footwear Sci. 2021:1-8.

94. Sobel E, Levitz S, Caselli M, Christos P, Rosenblum J. The effect of customized insoles on the reduction of postwork discomfort. J Am Podiatr Med Assoc. 2001;91(10):515-20.

95. Springett KP, Otter S, Barry A. A clinical longitudinal evaluation of prefabricated, semi-rigid foot orthoses prescribed to improve foot function. Foot (Edinb.) 2007;17(4):184-9.

96. Sterzing T, Barnes S, Althoff K, Determan L, Liu H, Cheung JT-M. Tennis shoe requirements in China, USA, and Germany. Footwear Sci. 2014;6(3):165-76.

97. Sterzing T, Müller C, Hennig EM, Milani TL. Actual and perceived running performance in soccer shoes: a series of eight studies. Footwear Sci. 2009; 1(1):5-17.

98. Sterzing T, Schweiger V, Ding R, Cheung JT-M, Brauner T. Influence of rearfoot and forefoot midsole hardness on biomechanical and perception variables during heel-toe running. Footwear Sci. 2013;5(2):71-9.

99. Walther M, Kratschmer B, Werschl J, Volkering C, Altenberger S, Kriegelstein $S$, et al. Effect of different orthotic concepts as first line treatment of plantar fasciitis. Foot Ankle Surg. 2013;19(2):103-7.

100. Wang Y, Lam WK, Cheung CH, Leung AK. Effect of red arch-support insoles on subjective comfort and movement biomechanics in various Landing Heights. Int J Environ Res Public Health. 2020;17(7):05.

101. Witana CP, Goonetilleke RS, Au EYL, Xiong S, Lu X. Footbed shapes for enhanced footwear comfort. Ergonomics. 2009;52(5):617-28.

102. Witana CP, Goonetilleke RS, Xiong S, Au EYL. Effects of surface characteristics on the plantar shape of feet and subjects' perceived sensations. Appl Ergon. 2009;40(2):267-79.

103. Yang B, Li Z, Zhou B, Olofsson T, Li A. Enhanced effects of footwarmer by wearing sandals in winter office: a Swedish case study. Indoor Built Environ. 2021;30(7):875-85.

104. Zifchock RA, Davis I. A comparison of semi-custom and custom foot orthotic devices in high- and low-arched individuals during walking. Clin Biomech. 2008;23(10):1287-93.

105. Zwaferink JBJ, Custers W, Paardekooper I, Berendsen HA, Bus SA. Effect of a carbon reinforcement for maximizing shoe outsole bending stiffness on plantar pressure and walking comfort in people with diabetes at high risk of foot ulceration. Gait Posture. 2021;86:341-5.

106. Teitz CC, Harrington RM, Wiley H. Pressures on the foot in pointe shoes. Foot Ankle. 1985;5(5):216-21.

107. McHenry RD, Arnold GP, Wang W, Abboud RJ. Footwear in rock climbing: current practice. Foot (Edinb.) 2015;25(3):152-8.

108. Jellema AH, Huysmans T, Hartholt K, van der Cammen TJM. Shoe design for older adults: evidence from a systematic review on the elements of optimal footwear. Maturitas. 2019;127:64-81.

\section{Publisher's Note}

Springer Nature remains neutral with regard to jurisdictional claims in published maps and institutional affiliations. 